\title{
Teaching Tools For Data Analysis
}

Katherine Chudoba, Utah State University, USA

Karina Hauser, Utah State University, USA

David Olsen, Utah State University, USA

\begin{abstract}
Companies rely on business intelligence and business analytics to support organizational decision making. Application software packages enable data analysis to help companies pursue a competitive advantage. Learning to use these tools is not trivial, however, and business schools have added assignments and classes to help their students develop rigorous analytical skills. This paper describes hands-on, data analysis exercises to support strategic decision making used in an Applied Business Research class that is required for MBA students. The assignment involves analyzing large volumes of data using the tools of Excel, SQL, and SPSS. We describe the assignment, data, and exercises that the students perform. They learn the benefit of analyzing a dataset using different tools and methods, and which tools are most appropriate for what type of analysis.
\end{abstract}

Keywords: Data analysis, business intelligence, Excel, SQL, SPSS, pivot table

\section{INTRODUCTION}

$\mathcal{J}$ oday, companies create vast amounts of transactional data, but unfortunately, many companies are "data rich" and "information poor". Converting data into knowledge to support the decision making process is the focus of the fields of business intelligence and business analytics. Beller and Barnett [8] consider the two as separate fields: business intelligence is concerned with answering predefined questions and creation of standard metrics and reports, and business analytics focuses more on exploration of new knowledge and investigative analysis. Davenport [9], on the other hand, considers business analytics as a subset of business intelligence. The overarching theme for both fields is that they use analytical methods, exploratory or predictive, to support datadriven, fact-based decision making in companies.

Vendors such as SAP, Oracle, and Cognos provide application software packages that enable users to analyze a company's data in order to achieve a competitive advantage [11]. For example, Earthgrains refrigerated dough division's earnings increased by $70 \%$ after analysis of product profitability [10]. Netflix makes extensive use of analytics tools to explore customer behavior and buying patterns. By analyzing previously watched movies, they can make suggestions to customers about which movies to rent next. Considering both a customer's preferences and the demand patterns for movies is a win-win situation for both parties [9]. American Airlines was an early adopter of business analytics in the 1980 's. Price optimization for seats sold to passengers is said to have increased revenue by 1.2 billion dollars over three years [14].

Other companies have taken note of these success stories. An IBM survey [12] showed the majority of companies surveyed recognized the need for better information management. $75 \%$ of the companies said that it was a critical priority for IT and the overall business to integrate data stored in different formats and locations so that it could be analyzed and support sharper, timelier decisions. This trend was consistent across all industries and countries.

Together, these examples suggest business analytics and business intelligence are important tools for companies that want to gain a competitive advantage in the marketplace. Learning to use the tools is not a trivial endeavor. Traditionally, managers have relied on domain knowledge in their specific area of expertise to guide decision making, but today, they often must rely on data analysts to create meaning from data stored in a company's database or data warehouse [13]. There is a great need for future managers to be trained in data analysis techniques. 
Universities have recognized that need. Some MBA programs $[4,5,7]$ have created specializations in Business Intelligence, and a few offer degrees in Masters in Business Intelligence [1,3] or Business Analytics [2, 6]. The vast majority of programs incorporate data analysis into one or more of their MBA courses. The exercises described in this paper are an integral part of an Applied Business Research that is required for MBAs at Utah State University. The class introduces students to the scientific method, including how to articulate a research question and hypotheses, design a study and use appropriate methods to evaluate the hypotheses, and analyze results and discuss the implications of the research findings. Students learn to apply the scientific method to address problems in marketing research, lean manufacturing process optimization, financial analysis, and fraud detection in accounting data.

This paper describes hands-on, data analysis exercises to support strategic decision making used in the Applied Business Research class. Students complete the exercises using three commonly available software tools: Excel, SQL and SPSS. The objective is for them to become familiar with multiple tools. The first section describes the assignment and data that serve as a basis for all the exercises. The next three sections give detailed insight into the Excel exercises, SQL exercises and SPSS exercises, followed by the conclusion.

\section{DESCRIPTION OF STUDENT ASSIGNMENT AND DATA USED}

Students are provided a dataset with almost 30,000 records and a series of questions to prime their exploration of the data. For example, they are asked to identify the salespeople who had the highest and lowest sales over a ten year period, and to perform various statistical analyses using the data. They are encouraged to go beyond answers to the set of questions and to perform a thorough analysis of the data. Students submit a ten-page paper that describes their review and includes a set of recommendations for management. They submit their statistical analyses and work papers (e.g., audit trail) in Appendices. Emphasis is placed on presenting the data in an appropriate manner (numbers vs. graphs) and clear written communication. The instructor seeds the data differently each semester. The assignment is worth ten percent of a student's overall grade.

The database used for all the examples consists of only one table, shown with sample data in Excel format in Table 1 and database table format in Figure 1. Since the emphasis is on data analysis and not database design the table is not normalized. This design makes data analysis in Excel and SPSS easier and avoids the task of joining tables in SQL, which is a challenge for students who are not familiar with databases.

Table 1: Excerpt from Excel Spreadsheet

\begin{tabular}{|c|c|c|c|c|c|c|c|c|}
\hline $\begin{array}{c}\text { Sales } \\
\text { PersonID }\end{array}$ & $\begin{array}{c}\text { First } \\
\text { Name }\end{array}$ & $\begin{array}{c}\text { Last } \\
\text { Name }\end{array}$ & Gender & Quarter & $\begin{array}{c}\text { Sales } \\
\text { Year }\end{array}$ & $\begin{array}{c}\text { Sales } \\
\text { Amount }\end{array}$ & $\begin{array}{c}\text { Quarterly } \\
\text { Bonus }\end{array}$ & Region \\
\hline 482 & Zoe & Mallory & F & 1 & 2007 & 35832 & 12108.23214 & Midwest \\
\hline 482 & Zoe & Mallory & F & 2 & 2007 & 48443 & 16369.69998 & Midwest \\
\hline 482 & Zoe & Mallory & F & 3 & 2007 & 21480 & 7258.451283 & Midwest \\
\hline 482 & Zoe & Mallory & F & 4 & 2007 & 7411 & 2504.300859 & Midwest \\
\hline 482 & Zoe & Mallory & F & 1 & 2008 & 17997 & 6081.487325 & Midwest \\
\hline
\end{tabular}

\begin{tabular}{|l|l|}
\hline \multicolumn{2}{|c|}{ Sales } \\
\hline PK & SalesPersonID \\
\hline & FirstName \\
& LastName \\
& Gender \\
& Quarter \\
& SalesYear \\
& SalesAmount \\
& QuarterlyBonus \\
& Region \\
\hline
\end{tabular}

Figure 1: Sales Table with Columns 
The original data is generated through a series of SQL statements and then exported to Excel. The SQL statements for creation of the table, filling the Year and Quarter column and two examples for filling in the personal data are shown in Listing 1.

The data is provided to the students in an Excel spreadsheet. Part of the student's SQL assignment is to import the Excel file into Microsoft SQL Server. An earlier lesson discusses different data formats and how to convert data from one format to another.

\section{DATA ANALYSIS USING EXCEL}

Analysis in Excel requires that students use both basic functions and more advanced methods. The functions and approaches described below are only one way to achieve the desired results.

\section{Data students report}

- $\quad$ Overall sales amount (using the SUM function)

- $\quad$ Overall bonus amount (using the SUM function)

- $\quad$ Sales amount and bonus amount by gender (using the SUMIF function)

- $\quad$ Sales amount and bonus amount by region (using the SUMIF function)

- $\quad$ Sales amount and bonus amount by quarter (using the SUMIF function)

For the next set of analyses, students must aggregate the data by SalesPersonID. To do that they need to:

- $\quad$ sort the data by SalesPersonID (using the SORT option in the Data tab)

- $\quad$ create subtotals by SalesPersonID (using the Subtotal option in the Data tab)

- $\quad$ copy the subtotals only into a new worksheet (by first hiding the detail, selecting the data, using F5 to change the default to "Visible cells only" and then copying the data into a new worksheet)

The first two actions are easily found in the Data tab of Excel, while the last one requires an Internet search if students are not familiar with it (e.g. http://excel.tips.net/Pages/T002647_Copying_Subtotals.html). The results of these actions are shown in Table 2.

Table 2: Data after Creating Subtotals by SalesPersonID

\begin{tabular}{|c|c|c|c|c|c|c|c|c|}
\hline $\begin{array}{c}\text { Sales } \\
\text { PersonID }\end{array}$ & $\begin{array}{c}\text { First } \\
\text { Name }\end{array}$ & $\begin{array}{c}\text { Last } \\
\text { Name }\end{array}$ & Gender & Quarter & $\begin{array}{c}\text { Sales } \\
\text { Year }\end{array}$ & $\begin{array}{c}\text { Sales } \\
\text { Amount }\end{array}$ & $\begin{array}{c}\text { Quarterly } \\
\text { Bonus }\end{array}$ & Region \\
\hline 128 Total & & & & & & 1206033 & 407538.7233 & \\
\hline 129 Total & & & & & & 1244417 & 420509.3189 & \\
\hline 130 Total & & & & & & 1167322 & 394457.6289 & \\
\hline 131 Total & & & & & & 1288148 & 435286.7552 & \\
\hline 132 Total & & & & & 1318018 & 445380.3279 & \\
\hline
\end{tabular}

The final step is to complete the FirstName, LastName, Gender and Region fields (using VLOOKUP). The Quarter and Sales Year columns are deleted because they would always display the first quarter and sales year found and so are not appropriately associated with the remaining data shown in Table 3.

Table 3: Data after VLOOKUP

\begin{tabular}{|c|c|c|c|c|c|c|}
\hline $\begin{array}{c}\text { Sales } \\
\text { PersonID }\end{array}$ & $\begin{array}{c}\text { First } \\
\text { Name }\end{array}$ & $\begin{array}{c}\text { Last } \\
\text { Name }\end{array}$ & Gender & $\begin{array}{c}\text { Sales } \\
\text { Amount }\end{array}$ & $\begin{array}{c}\text { Quarterly } \\
\text { Bonus }\end{array}$ & Region \\
\hline 128 Total & Jason & Perry & M & 1206033 & 407538.7233 & Northeast \\
\hline 129 Total & Jennifer & Adams & F & 1244417 & 420509.3189 & Midwest \\
\hline 130 Total & Austin & Richardson & M & 1167322 & 394457.6289 & Northwest \\
\hline 131 Total & Elisa & Smith & F & 1288148 & 435286.7552 & Southwest \\
\hline 132 Total & Hary & Potter & M & 1318018 & 445380.3279 & Southeast \\
\hline
\end{tabular}




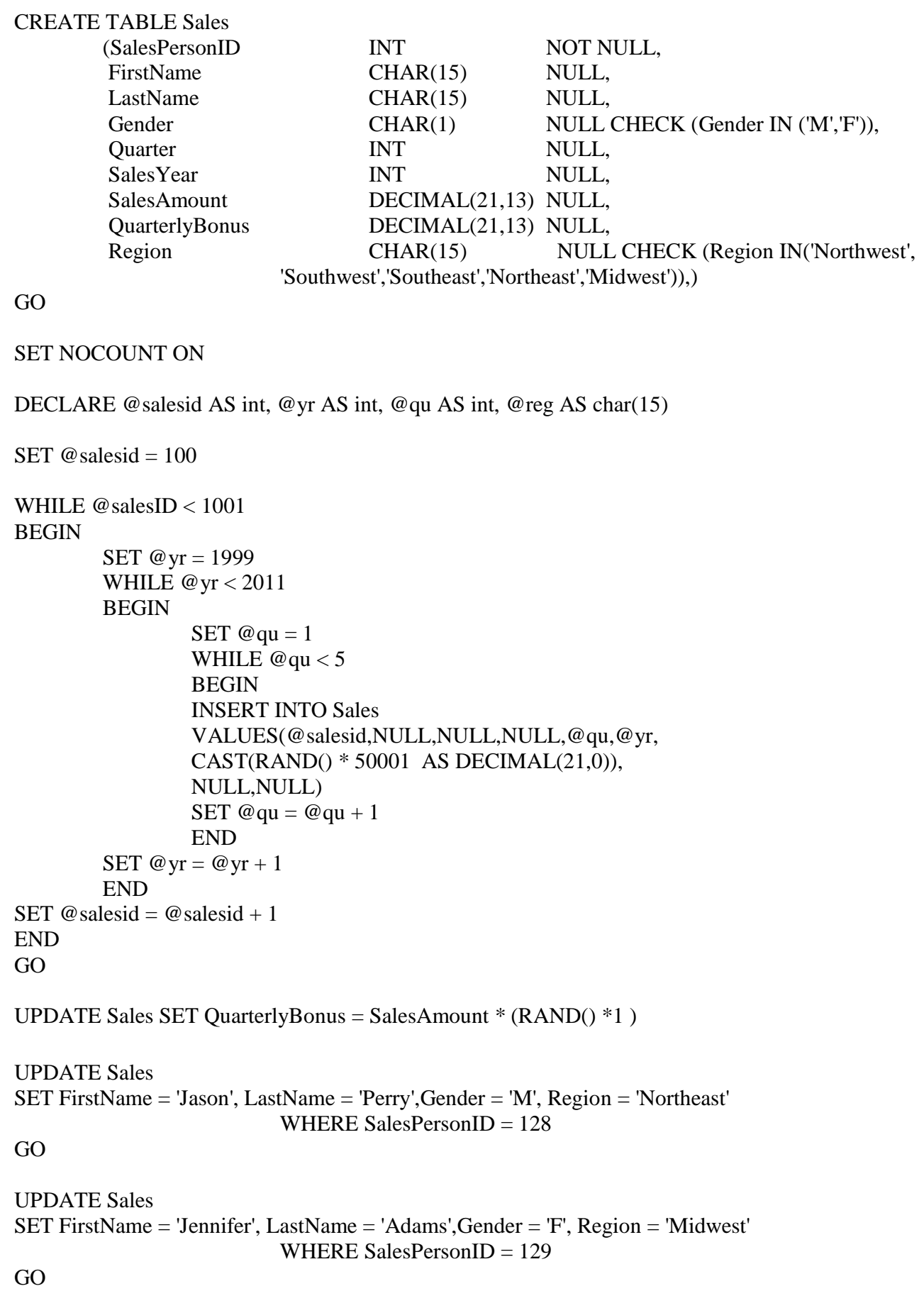

GO

SET NOCOUNT ON

DECLARE@salesid AS int, @yr AS int, @qu AS int, @ reg AS char(15)

SET @ salesid = 100

WHILE @ salesID < 1001

BEGIN

SET @yr=1999

WHILE@yr $<2011$

BEGIN

SET @ qu =1

WHILE@qu $<5$

BEGIN

INSERT INTO Sales

VALUES(@salesid,NULL,NULL,NULL,@qu,@yr,

$\operatorname{CAST}(\operatorname{RAND}() * 50001$ AS DECIMAL $(21,0))$,

NULL,NULL)

SET@qu=@qu+1

END

SET @yr=@yr + 1

END

SET @ salesid = @ salesid + 1

END

GO

UPDATE Sales SET QuarterlyBonus = SalesAmount $*(\operatorname{RAND}() * 1)$

UPDATE Sales

SET FirstName $=$ 'Jason', LastName $=$ 'Perry',Gender $=$ 'M', Region $=$ 'Northeast'

WHERE SalesPersonID $=128$

GO

UPDATE Sales

SET FirstName $=$ 'Jennifer', LastName $=$ 'Adams',Gender $=$ 'F', Region $=$ 'Midwest'

WHERE SalesPersonID $=129$

GO

\section{Listing 1: SQL Statements To Create Data}

After these analyses, students are able to report the following information:

- $\quad$ Overall number of sales persons

- $\quad$ Number of female/male sales persons (using the COUNTIF function) 
- $\quad$ Number of sales persons per region (using the COUNTIF function)

- Determine the sales person with the highest/lowest sales amount and bonus amount (using the MAX/MIN function)

- $\quad$ Average sales amount and bonus amount

- $\quad$ Number of sales persons below/above average

- $\quad$ Average sales amount and bonus amount by gender

- $\quad$ Average sales mount and bonus amount per region per sales person

Students create a subtotal by year to provide the following data:

- $\quad$ Yearly sales amount and bonus amount

- $\quad$ Trend line, regression equation and $\mathrm{R}^{2}$ of regression analysis

Adding region as another subtotal within the year will create

- $\quad$ Sales amount and bonus amount by region by year

Table 4: Excerpt of Pivot Table, Filtered by Region and Gender

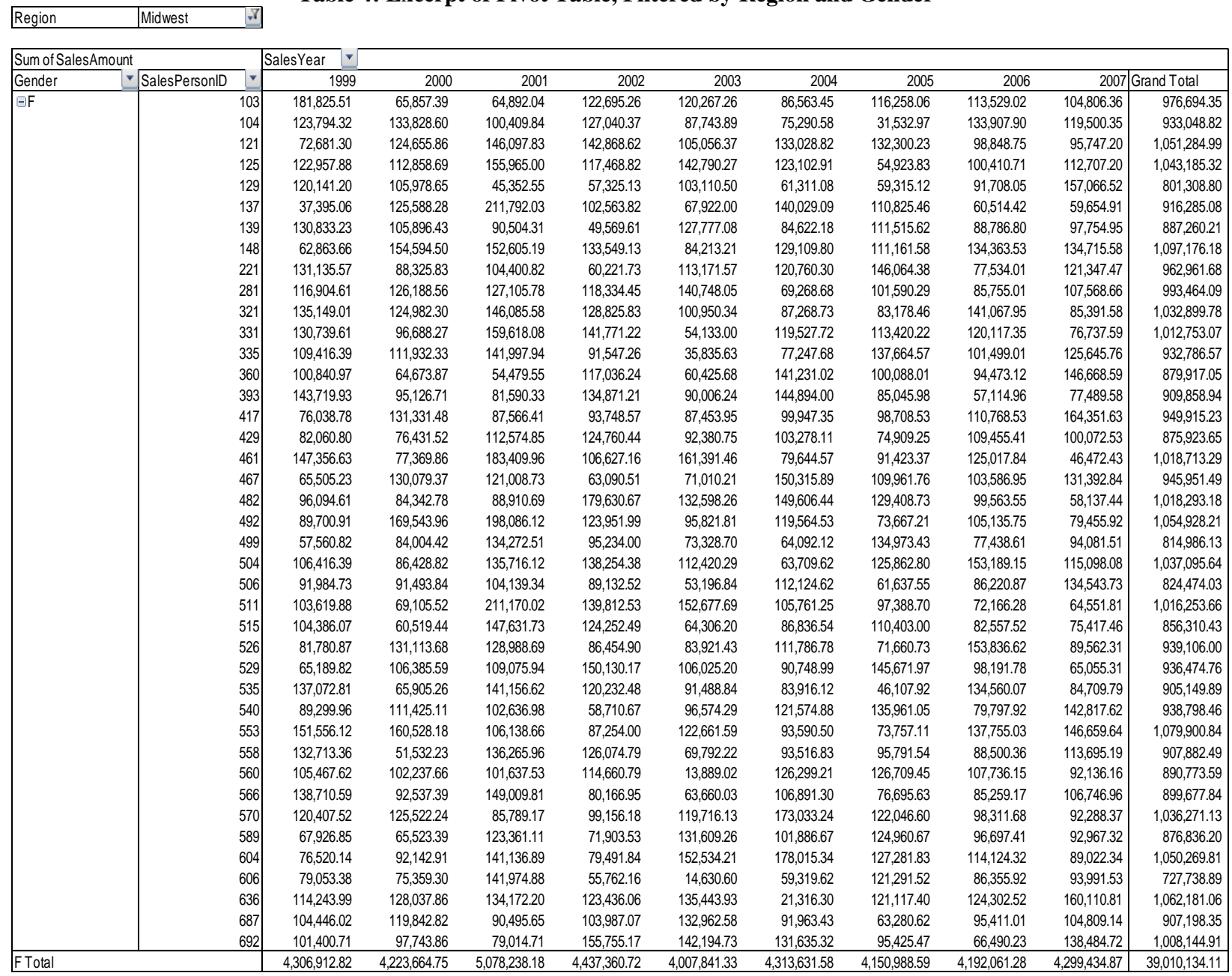




\section{DATA ANALYSIS USING EXCEL PIVOT TABLES}

In addition to analyzing the data using formulas and scenario tools, students must demonstrate mastery of the pivot table function in Excel. Once students have created a pivot table (using Insert/Pivot table), they can explore different ways of manipulating the data by adding attributes to the column (e.g., year), row (e.g., region), and values (e.g., sales) section of the pivot table report. Assignment questions lead students to apply filters to fields (e.g., gender, region), add report totals, and add formulas or calculated fields. Once students identify an interesting relationship or trend in aggregated data, they quickly learn how easy it is to drill down into the data to explore and understand the reasons behind the relationships. They learn that aggregating data by variables such as sales person ID and gender are trivial tasks when done using a pivot table, and that pivot tables make it much easier to dynamically manipulate data and search for the explanation behind interesting relationships.

\section{Graphs students create}

One objective of the assignment is for students to make judgments about what data is best represented in tables and what data is best represented in charts and graphs. For example, they should realize that it is best to display regional data in a pie or column chart and yearly data in a trend chart. Of course, Excel makes it easy for students to create visual representations of their analyses, as shown in Figure 2.

Figure 2: Sample Charts and Graphs Created in Excel
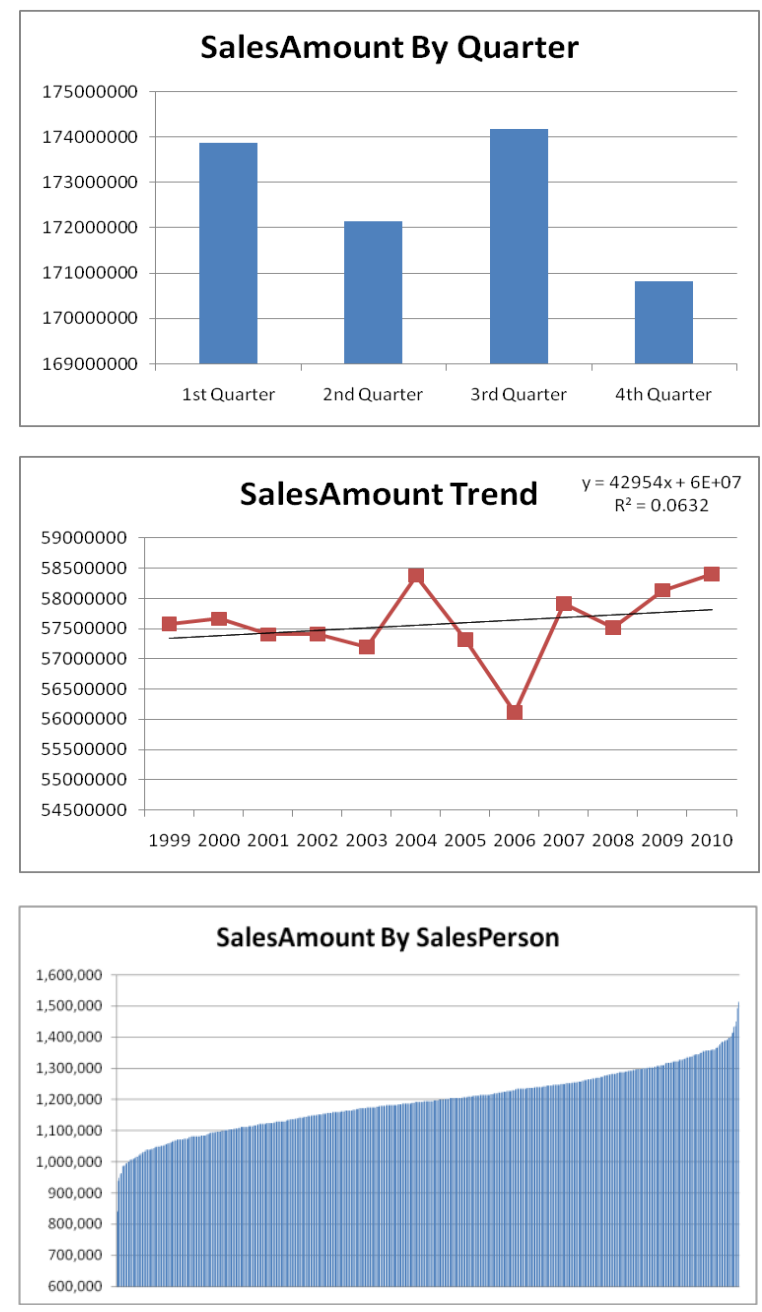
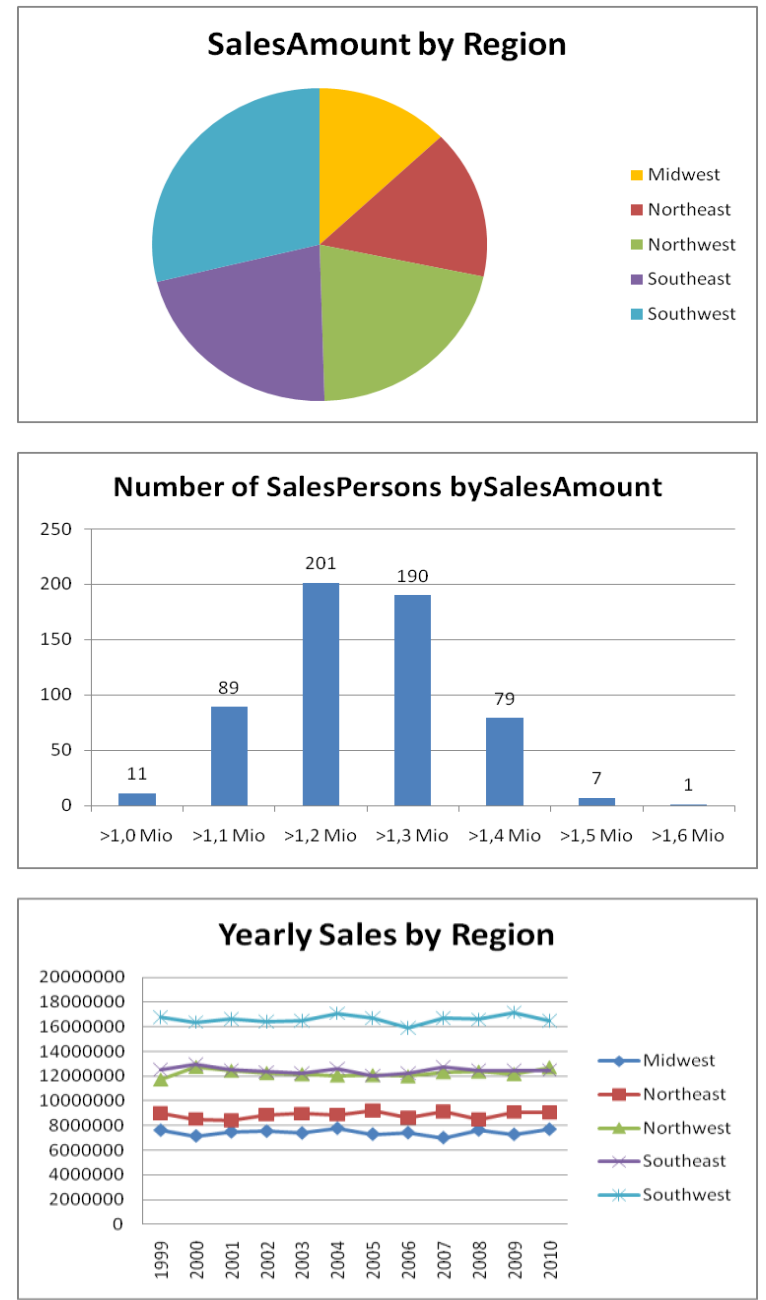


\section{DATA ANALYSIS USING SQL}

As mentioned earlier, students are required to import the data into a SQL database and change the data types to be appropriate for analysis. For example, they must ensure that all fields that contain numbers are represented as numerical fields and have the right amount of decimals. Since most students have only limited or no experience with SQL, a variety of SQL statements with descriptions about their functions are provided by the instructor. Some examples are included in Listing 2. Most students are able to adjust the queries for the analyses they need to create.

List all attributes of the sales table as well as all tuples/ SELECT * FROM Sales;

Find the average quarterly sales amount. Name this new column AverageSalesAmount. SELECT AVG(SalesAmount) AS AverageSalesAmount FROM Sales;

List the total amount of sales for each quarter for each sales year. Put your answer in order of year and then quarter in ascending order.

SELECT SalesYear, Quarter, SUM(SalesAmount) AS TotAmt FROM Sales

GROUP BY SalesYear, Quarter

ORDER BY SalesYear, Quarter;

Write a stored procedure that lists the sales person's id, first name and name for the person whose id is input as a parameter.

CREAT E PROCEDURE ChooseSalesPerson (@ID INT) AS

SELECT SalesPersonID, FirstName, LastName

FROM Sales WHERE SalesPersonID = @ ID;

To run the stored procedure:

EXEC ChooseSalesPerson 305

Listing 2: SQL Statements Provided to the Students

In the SQL portion of the assignment, students discover that they can get answers to the same questions they answered using Excel, but with less time and effort involved. The grouping by salesperson that required several steps in Excel is done with a single SQL statement. For example, the overall number and the number of female/male sales persons can be easily determined with the SQL statements in Listing 3: Example SQL StatementsListing 3.

Overall number of sales persons

SELECT COUNT(DISTINCT SalesPersonID) FROM Sales;

Number of female/male sales persons

SELECT Gender, COUNT(DISTINCT SalesPersonID) from Sales

GROUP BY Gender;

Listing 3: Example SQL Statements

The inclusion of an example of stored procedures shows students that the user is not required to input the statements every time and also that the SQL statement could be prepared by somebody with extensive database knowledge and then simply executed by the person who needs the results. Students also discover that some of the statistical analysis options, included in Excel, are not available in standard SQL and so they must perform these analyses using SPSS. 


\section{DATA ANALYSIS USING SPSS}

SPSS Statistics is a commonly used statistical analysis program that is installed in all computer labs at Utah State University. It allows user to import different data formats, Excel being one of them.

SPSS has an option to aggregate data which makes tasks that required sorting and creating subtotals in Excel very easy. For example, using SalesPersonID, FirstName, LastName, Gender, and Region as the Break Variables and SalesAmount, QuarterlyBonus as aggregate variables, user can create a wide variety of aggregate function as shown in Figure 3.

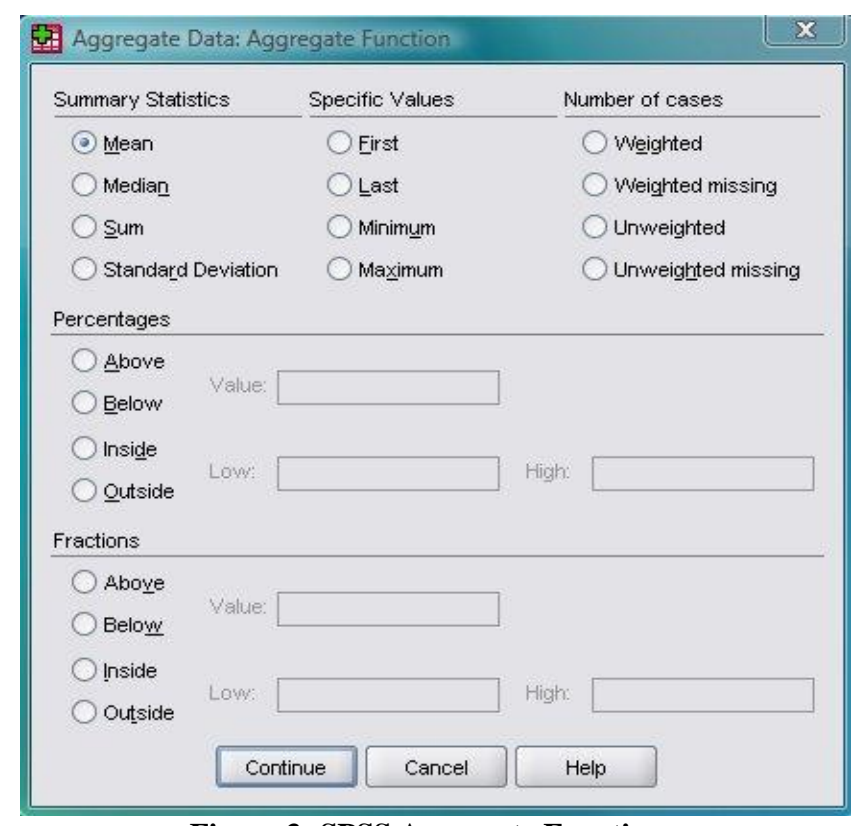

Figure 3: SPSS Aggregate Functions

SPSS also offers a user-friendly Chart Builder that includes some unique graphs, such as a histogram split by gender, illustrated in Figure 4.

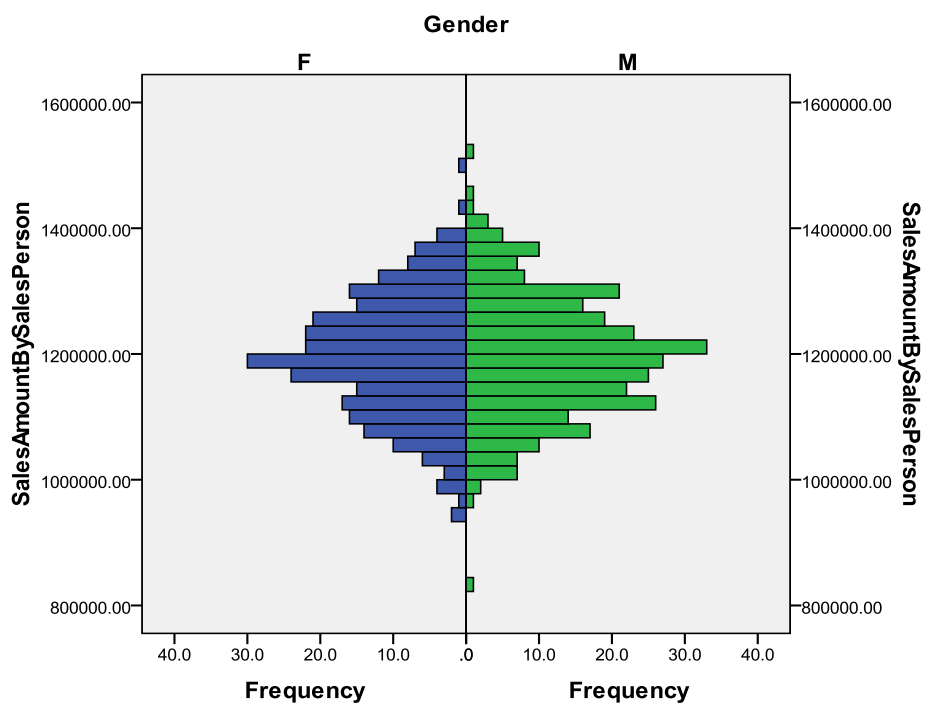

Figure 4: SPSS Graph, Split Histogram 
Conducting a T-test or ANOVA can be done by simply entering the Test Variable and Grouping Variable. The sophistication of the SPSS analyses the students are able to complete depend largely on their statistical knowledge and creativity.

\section{INSIGHTS STUDENTS SHOULD GLEAN FROM THEIR ANALYSES}

As mentioned earlier, the instructor can reseed the dataset every semester, so the results discussed below will vary. They point, however, to the kinds of analyses students are expected to complete above and beyond answering the explicit questions that they are asked to answer using Excel, SQL, or SPSS.

- $\quad$ The overall sales amount and bonus amount is higher for the male salesperson but the average is nearly the same. This initial finding should be supported by a t-test showing that there is no statistically significant difference between the groups.

- $\quad$ There is a large difference (>100\%) between the best performing region and the lowest one.

- $\quad$ The yearly sales amount by region is stable, with no up/downward trends.

- $\quad$ The difference between the highest performing salesperson and the lowest one is nearly $100 \%$.

- $\quad$ Only 11 salespersons sold less than 1 million dollars

- Nearly half of all salespersons are below average and half above (e.g., mean and median are almost identical).

- $\quad$ The total sales amount fluctuates by quarter. Students need to perform an ANOVA test to reveal that there is no statistically significant difference between the groups.

- $\quad$ Whereas the trend line shows an upward trend the regression analysis reveals that the fit is not very good. In the example shown only $6.32 \%$ of the total variance can be "explained" by the linear regression model. That leaves the rest of the variance ( $\sim 94 \%$ of the total) as variability of the data from the model.

\section{CONCLUSIONS}

The data analysis assignment that our MBA students complete gives them experience in managing and analyzing large volumes of data using the tools of Excel, SQL, and SPSS. For example, it is somewhat cumbersome to create subtotals in Excel, but straightforward to do so in SQL and SPSS. Performing an ANOVA in Excel is a lengthy process because the data need to be rearranged so that each quarter appears in a separate column. Students learn the benefits of being able to analyze data and get the same results using different tools and methods, and which tools are most appropriate for what type of analysis. They also gain an appreciation of the amount and level of data needed to make informed decisions in business. A company's competitive advantage will depend on how data is used to support these decisions.

\section{AUTHOR INFORMATION}

Katherine M. Chudoba is Associate Professor of MIS in the Jon M. Huntsman School of Business at Utah State University. Her research focuses on the nature of work in distributed environments, and how Information and Communication Technologies (ICTs) are used and integrated into work practices. She has published in journals such as MIS Quarterly, Organization Science, and Information Systems Journal. She earned her Ph.D. at the University of Arizona, and her bachelor's degree and MBA at the College of William and Mary. Before joining academe, she worked as an analyst and manager with IBM.

Karina Hauser is an associate professor in the Management Information Systems department at Utah State University. She received her PhD in Decision Science and Information Technology at the University of Kentucky on a Toyota Fellowship. Her research interests are in Web Development, Web Design and Lean Manufacturing. Before going into academia, Karina spent 16 years in industry, first as a programmer and later as a consultant and project manager for Enterprise Resource Planning systems, mainly in the automotive sector. Her research appeared in journals such as the Journal of Information Systems Education, Journal of Computer Information Systems, and International Journal of Production Research. 
David Olsen received his Ph.D. in Management Information Systems from The University of Arizona in 1993 and taught at The University of Akron accounting department in accounting information systems for five years. Dr. Olsen joined the MIS department at Utah State University in 1998 and teaches primarily in the database area as well as the MBA strategy and management course. His research interests include database concurrency control, accounting information systems, the integration of SQL, XML and XBRL, and database modeling. His research has been published in journals such as Communications of the ACM, Issues in Accounting Education, and the Journal of Database Management. Dr. Olsen is happiest with regards to the teaching awards he has received.

\section{REFERENCES}

1. Master's Degree in Business Intelligence vs. MBA: Which is More Relevant to Today's Workplace? [cited 11/15/2009]; Available from: http://www.sju-online.com/articles/masters-business-intelligence.asp.

2. Master in Business Analytics. [cited; Available from: http://soms.utk.edu/analytics/index.htm.

3. Master of Science Business Intelligence. [cited; Available from: http://www.americansentinel.edu/onlinedegree/online-masters-degree/masters-business-intelligence.php.

4. $\quad \mathrm{MBA}$ in Business Intelligence. [cited; Available from: http://www.lsbf.org.uk/programmes/masters/mba/intelligence.html.

5. MBA with Business Intelligence Concentration. [cited; Available from: http://spears.okstate.edu/management/degrees/mba/concentrations/intel.

6. Msc in Business Analytics. [cited; Available from: http://www.smurfitschool.ie/specialistmasters/technology/mscinbusinessanalytics/.

7. Specialize in Business Intelligence. [cited 2009/11/17]; Available from: http://business.cudenver.edu/Graduate/ProMBA/Track_BusinessIntelligence.htm.

8. Beller, M. and A. Barnett. Next Generation Business Analytics Technology Trends. 2009 [cited 11/23/2009]; Available from: http://www.scribd.com/full/16588686?access_key=key14sahazncp852mcpammn.

9. Davenport, T.H. and J.G. Harris, Competing on Analytics.Boston, MA: Harvard Business School Press.

10. Davenport, T.H., et al., Data to Knowledge to Results: Building An Analytic Capability. California Management Review, 2001. 43(2): p. 117-138. 2001

11. Gnatovich, R. Business Intelligence Versus Business Analytics -- What's the Difference? 2006 [cited 11/23/2009]; Available from: http://www.cio.com/article/18095/Business_Intelligence_Versus_Business_Analytics_What_s the Differe nce_?page $=1$.

12. IBM, Inside the midmarket: A 2009 Perspective, I.W. Study, Editor. 2009.

13. Kohavi, R., N.J. Rothleder, and E. Simoudis, Emerging trends in business analytics. Commun. ACM, 2002. 45(8): p. 45-48. 2002

14. Smith, B.C., et al., E-Commerce and Operations Research in Airline Planning, Marketing, and Distribution. Interfaces, 2001. 31(2): p. 38-55. 2001 